\title{
Discussion on the Aesthetic Style of "Memphis" Design
}

\author{
Lin Tang \\ College of Architecture and Design \\ Southwest Jiaotong University \\ Chengdu, Sichuan, China 611756 \\ Academy of Fine Arts \\ China West Normal University \\ Nanchong, Sichuan, China 637002
}

\begin{abstract}
In the late 1960 s of 20 th century, the postmodernist design which originated from construction field quickly spread to Italy, and emerged a large number of Radical Design organizations with "Memphis" as the particularly famous one. Radical Design is against the view of rationalist design, it emphases to integrated more artist's personal style and cultural meaning into the design. "Memphis" bring in some fresh air to the design community, some people criticized the "Memphis" taste but also get some inspiration in the same time. This article will analyze the aesthetics ideology and aesthetic style from social, philosophical and aesthetic background which created from the "Memphis" design.
\end{abstract} style

Keywords-"Memphis" design; aesthetics ideology; aesthetic

\section{INTRODUCTION}

Italian Radical Design (Radical Design) appeared in the late 1960s of 20th century, its basic tendency is to go against with rationalism design concept, emphases to integrated more artists' personal style and cultural meaning into the design. Because of its opposition to modern rationalism and functional, it claimed itself as "anti-design" (Anti-design). In 1969, Italy suffered a severe economic crisis and the subsequent oil crisis even worse. This has forced the Italians to raise $\mathrm{R} \& \mathrm{D}$ capabilities to enhance the taste of furniture, fashion, leather goods and household appliances to win foreign markets. In addition, during the late 1960s and early 1970s, the Western society is unrest, anti-war demonstrations, labor strikes, disintegration of the Soviet Union, the global ecological crisis, AIDS and drug abuse, post-modernism, the rise of new society movements, globalization ... All of the new things strongly stimulate the sensitive nerve of the intellectuals. In the late 1960s, some architects and designers from Rome, Milan, Turin, and Florence have made a number of radical design ideas. They accepted the influence of United States and Britain's Pop Art, Neo-Dadaism and Surrealism, and they made proposals like "work for humanity, not for economic goal", "create for improving the quality of life not simply for increasing the accumulation of capital", they against with Italy traditional design, especially developed since the war for the high-income groups, the so- called "elegant design (Bel Disegno)". [1] "Memphis" design team is one of the most representative team among these radical design communities.

\section{THE EMERGENCE AND DEVELOPMENT OF"MEMPHIS"}

"Memphis" is the most influential organization in Postmodernism design community, its formation has some accidental factors but not an accidental event, its formation is inevitable. At the same time its development and transformation also are the inevitable result of the era development and design progress. "Memphis" design group should be established in the evening of 11th December 1980, and its establishment is closely related to a person, that is, Ettore Sottsass. When Sottsass party with other 7 designers who later became "Memphis" members, when listening to Bob Dylan singing "Memphis Blues Again", suddenly Sottsass decided to establish a design group called "Memphis". "Memphis" means melancholy blues, Tennessee, rock, suburban America, as well as the distant Egypt, the Pharaoh's capital, the holy city of God. [2]

September 18th1981"Memphis" was established, their different works made the audience showed a fanatical response for this exhibition. These works with bright colors and colorful decorations, although with some strange, but it looks lively; they won the people's favorite. Through this sensational exhibition, this suddenly became famous organization and its exploration in design field, has became the most eye-catching postmodern design activities in 1980s, and it made this design movement which brew a long time to reached a climax.

\section{The Aesthetics IdeOlogy AND AESTHEtic StYle OF "MEMPHIS" DESIGN}

\section{A. PoeticDesign Philosophy}

In Memphis opinion, the whole art design community had promoted the functionism, Bauhaus ideology, Futurism, etc. since the establishment of Bauhaus art from 1960s and 1970 s to the later several are attempt to give a speculative, logical and rational conclusion for design principle. Design services the production and living, so invisibly formed a 
stereotyped lifestyle. Memphis disagrees with the design philosophy and lifestyle which modernist design advocated. They believe the world is known by emotion, there is no priori model waiting for designers to explore. Sottsass said: "The world is a place found by senses, and I shall not talk about a certain kind of form, but just made a gesture. Designed for me, is a channel to discuss about life, society, politics, food and even design itself."[3] Design is no longer a conclusion, but a hypothesis; not a declaration, but a step, a moment. There is no certainty, only possibility; there is no truth, only empirical; there is no "What is that", only "what happened." In this way, Memphis has created an open design philosophy which ignores all patterns, breaking all box in modern society, it has a bright contrast with the functionaloriented design theme in modernist design.

\section{B. Neofunctionalism}

The relationship between design form and design function is the focused problem in modernist design, "less is more", "form follows function" are the main ideas of modernist design. Modernism's study of product features promote the ergonomic development to meet the ergonomic requirements in math and physics, it has also become modernist design goal. But Sottsass believes that this is a misunderstanding. He said: "When you are attempting to prescribe a product's feature, the feature is missing from your finger because the function has its own life. Functions can not be measured, and it is a possibility between the product and life. When Charles Yeames designed his chair, he did not really design a chair, but designed a sitting posture. In other words, he designed a function, designed for a function. He believes that function is not a physiological or physical system but a culture system. Designer's responsibility is not to achieve function but to discovery the function. "Design is a positive, human behavior modification method." [4] One of Memphis members, young designer Bolanqi said: "The new function is the new freedom." From this perspective we can understand the function so the designers' work can be liberated from the cold, grim calculations and formulas and toward optimism, determined, enthusiastic new realm like a poet and painter. "Memphis" design philosophy has been influenced by the popular theory. The theory believes that: the designer should be sought in the form of popular culture, designed to meet the requirements of the popular and according to the well-known popular views in order to meet certain public recognition type.

\section{Multi Semantic of Product Symbol}

Memphis designers have inherited the principle of Alchimia, which pay attention to product culture connotation, and they accepted influence of symbolism theory. They deny the product form, function and material should have interdependent relationship which proposed by the rationalism, Memphis thought that the three can exist independently, and rational can not unified the pluralistic world. Function is only one relationship between the product and life, form are not just for expressing function, form itself is a metaphor symbol. You can express specific cultural connotations, thus a product which has contradiction with form and function, as long as it expresses a unique culture and fun and delightful, then it has existence value. They think: from the perspective of semiotics, design refers to a processing method; product is a conscious information carrier, a metaphor or a symbol of a culture system. A designer, when he completed the design of a product, he not only affirm product with a use value, but also affirm a certain kind of value indicators with specific cultural connotations. Products designed by designers can be seen as a symbolic tool, it helps to create meaning during contacting with the environment. When the design work finished, it has functional and symbolic features. People can understand the work through its form and non-verbal intuition, also can understand it from the language and symbolic aspects carried historical and cultural factors. Memphis designers in the design of the works always trying to pursue a form of symbolic notation, they borrowed the view of semiotics, consider the design as a language to emphasize its multiple expressions, to pursuit the connection between form and symbolic meaning. Its design philosophy is: design works' sense of meaning is a fundamental need to design. For materials, Memphis designers not only see it as a material guarantee of design, but inject human connotation into the material and seen as a positive emotional exchange media, such emotional rather than rational manner will not regard the realistic of the material. Marble like plastic, or plastic like wood, in Memphis opinion it does not matter, the important thing is the material texture, pattern, color, density, transparency, luminosity, reflectivity and expressive ability they have. They have no material prejudice, they use everything as material and they combine cheap materials together with precious materials; combine rough materials together with smooth materials; combines light emitting material together with non-luminescent materials, and emphasize that all the elements are summarized in the basic form of square, circle and triangle and basic color of red, yellow and blue. They use wood, plastic, metal and other materials to be used as a creative combination of words, so that the products become a harmonious complex system. On the one hand, Memphis product design uses a specific visual image design to imply abstract concepts; on the other hand it reflects some symbolic meaning in visualization. But the meaning and the image is not entirely consistent. Symbolic understanding is ambiguous and changing, designers want their design theme has multiple interpretations, also strive to design emblematic design ideas, make people feel deeper and more cultural connotation and social value through implication, association and recall.

\section{Decoration Is Not Evil}

Functionalist slogan "decoration is evil" (Luce language) was criticized by Memphis. Memphis designers attached great importance to decoration; they consider decoration as a component part of design, like the texture of wood is determined by the internal structure. Mitchell da Lu Qi said: "The materials and decoration are the cells composed the product, we should do more cell research than the product." They believe that functionalist against decoration because their rational and logic attitude to design. "Times have changed the relationship between man and the world becomes more complex, more flexible, less didactic, less 
seriousness. Therefore, the decoration times is coming again." George Sooden said: "decoration belongs to the electronic age, as functionalism belongs to the Mechanical age." [5] Memphis designers generally use abstract patterns to decorate; it covered the surface of the product to change the product from static into active dynamic structure. They also have independent thinking about the surface color, they think color is the most rapidly, most direct way and with the most rich emotions to convey product information. But they do not like to look the chromatics rule and color matching laws set by modernist, they often do not distinguish between what is the main color, what color is off, and prefer to use very different color tones in parallel, resulting in a flutter visual effects, even at the cost of interference with each other to create a funny, witty, playful postmodern mood, resulting in serious and facetious effect. Sottsass declared: "Memphis furniture is very touching, it can only be together with people with blazing feelings, and highly developed, selfimprovement people, perhaps these people understand how to live in society without any institutional or cultural protection."

\section{INFLUENCE AND INSPIRATION OF "MEMPHIS"}

"Memphis" design provided the discussion topic which do not have result until now, many of their lack of function and brightly colored design products although became museum collections, but did not become a part of life to millions of households. As for life supplies, meet the functional requirements should be the premise to become consumer products, but obviously a lot of "Memphis" works lack of these basic requirements. But the "Memphis" brought some fresh air into design community, so that some people criticized the "Memphis" taste and also gets some inspiration or subjected to some kind of shock, began to rethink the modern design concept of functionalism, which formed in the past century. Slowly, postmodernism gradually decline because it does not have practicability and lack of basic survival, but new and unique product design has continued to produce ,their anti-modernist design feature is very obvious and also gradually been accepted. Post-modern design philosophy and aesthetic principles has gradually deep into the minds of designers and consumers.

\section{REFERENCES}

[1] G. Eason, B. Noble, and I.N. Sneddon, "On certain integrals of Han Wei Memphis design [M] Nanchang: Jiangxi Fine Arts Publishing Company, 2001, P23.

[2] Wang Shouzhi The world modern design history [M] Beijing: New Century Press, 1995, P50.

[3] Han Wei Memphis design [M] Nanchang: Jiangxi Fine Arts Publishing Company, 2001, P43

[4] Cao XiaoouForeignPost-modern design [M] Nanchang: Jiangxi Fine Arts Publishing Company, 2000, P96.

[5] Liang Mei Italian design [M] Chengdu: Sichuan People's Publishing Company, 2000, P132. 